\title{
Navbermedyayî: Di Edebiyatê De Arasteyeke Nû û Ji Edebiyata Kurdî ya Kurmancî Çend Mînak
}

\section{Mehmet Emin PURÇAK ${ }^{1}$}

\section{Medyalararasilik: Edebiyatta Yeni Bir Yönelim ve Kürt (Kurmanci) Edebiyatindan Birkaç Örnek}

Öz

Bu çalışmada medyalararasılık tekniğinin tanıtılması, edebiyat metinlerinde nasıl kullanıldığının tespiti ve edebiyat metinlerine etkisinin incelenmesi amaçlanmıştır.Bunun için öncelikle medya ve yeni medya kavramları üzerinde durulacaktır.Medya kavramının etimolojisine, kavramın geniş ve dar anlamdaki kullanımlarına, medyalararasılık teriminin ortaya çıkış süreci, farklı medya alanlarının birbiriyle ilişkisi ve alışverişine değinilecektir.Daha sonra medyalararasılık teriminin anlam ve kapsamına odaklanılarak edebiyat metinlerinde medyalararasılıktan nasıl yararlanıldığı, Kürt edebiyatında öne çıkan bazı eserlerden hareketle farklı medya öğeleri tespit edilerek bunların nasıl kullanıldığı gösterilecektir. Bu çerçevede Bîra Qederê, Gerîneka Guernicayê, Belkî Îșev Binive, Şevekî Îstîsmar, Fîtnevîzyon, Tarantîno Bavê Min û Ez, Hêvî û Têkoşîn, Saturn, Pirça Winda ûCemîlê Nîgarkêş û Heft Qambihostên Dewletê isimli eserlerde medyalararasılık ilişkileri üç başlık altında incelenecektir. Illk olarak roman ve hikâyede fotoğrafın kullanılması; ikinci olarak roman, hikâye ve şiirde sinema ve televizyonun kullanılması ile üçüncü kategoride daha çok internet medyasının hayatımıza dahil ettiği whatsapp, instagram, youtube, facebook gibi yeni medya unsurlarının edebiyat metinlerinde anılması ya da bunların edebiyat metinlerine etkisi, adı anılan eserler bağlamında tespit ve tahlil edilecektir. Bunun için karşılaştırma yönteminden yararlanılacaktır.

Anahtar Kelimeler: Medya, Yeni Medya, Medyalararasılık, Hibrit Metin, Kürt Edebiyatı.

Dr. Öğr. Üyesi, Muş Alparslan Üniversitesi, Fen Edebiyat Fakültesi, Kürt Dili ve Edebiyatı Bölümü, epurcak@hotmail.com, ORCID: 0000-0003-1875-5842. 


\title{
Intermedia: A New Trend in Literature And a Few Examples From Kurdish (Kurmanji) Literature
}

\begin{abstract}
In this study, it is aimed to introduce the technique of intermedia, to determine how it is used in literary texts, and to examine its effect on literary texts. For this reason, the concepts of media and new media will be handled first. In this section, the etymology of the concept of media and its broad and narrow uses will be discussed. Then, the emergence of the term intermedia, the relationship, and the exchange of different media fields will be dealt with. Following this step, focusing on the meaning and scope of the term intermedia, how it is utilized in literary texts will be shown and different media elements will be determined based on some prominent works in Kurdish literature and how they are used will be explained. Within this framework, inter-media relations will be examined under three headings in the works named Bîra Qederê, Gerîneka Guernicayê, Belkî Îşev Binive, Şevekî Îstîsmar, Fîtnevîzyon, Tarantîno Bavê Min û Ez, Hêvî û Têkoşîn, Saturn, Pirça Winda, Cemîlê Nîgarkêş û Heft Qambihostên Dewletê. Firstly, the use of photography in novels and stories; secondly, the use of cinema and television in novels, stories and poetry, and in the third category, the mention of new media elements such as whatsapp, instagram, youtube, facebook, which are mostly included in our lives by the internet media, in the literary texts or their effects on the literary texts will be determined and analyzed in the context of the mentioned works. While doing this, the comparison method will be used.
\end{abstract}

Keywords: Media, New Media, Intermediality, Hybrid Text, Kurdish Literature.

\section{Extended Abstract}

Telling stories is a necessity. For thousands of years, people have been transferring certain features of their lives to future generations by telling stories. Among them are hunting techniques, as well as religious rituals and beliefs. In addition, lifestyles, social statuses, human-nature relationship, management styles, apparel and food cultures are also included in these stories. In this way, the storyteller conveys many features of society through the story. The transfer of knowledge and culture does not ocur only with literature. We need various mediators to convey our feelings and thoughts. We can list them as follows: language, writing, painting, music, architecture, cinema, radio, television, gestures and mimes, sculpture, newspaper and etc. These elements in the position of intermediary are called media. Some media such as shamans, prophets, healers belong to primitive times. They intermediate without the need for a specific technical tool. Prayers, words believed to be magic, songs, and dances are also elements that support the shaman or help him to concentrate. Cave paintings are the first examples of written expression 
and written media. Visuality and meaning are intertwined in them. However, with the advancing technique, the role and form of intermediaries also change. Written culture, which developed after the invention of writing, has progressed rapidly. The invention of the printing press and its becoming so widespread has enabled readers to access text and books in cheaper ways and more easily. Thus, every technical progress has led the media to enter our lives more and more. Besides the now classic media such as literature, books, magazines and newspapers, new media organs have also had great impacts on people. The invention of photography in the first half of the nineteenth century and cinema in the second half of it increased the effect of the visual media. Visual culture has drawn more and more attention in the face of written culture. In addition to these, the use of telegraph and telephone in communication is also an important development. All these fed and advanced each other. The twentieth century was almost a cinema century, and the transition from a few seconds of footage to hours of silent cinema was realized. Again, the invention of radio, sound films, records and then cassettes, videocassettes and finally inventions ranging from $C D$ and DVD technology to cloud technology were experienced. Undoubtedly, these are all related, mutually supportive developments. For example, while photography conveys only the image, cinema added movement to it. While the radio transmitted pure sound, sound cinema and sound and image were used together. The photos were first colored in black and white. While movies were only watched in movie theaters, they were introduced to all homes through television, video cassette, CD and DVD. Computer usage became widespread especially after 1990's and internet usage became widespread after 2000's. This has led to changes and transformations in many areas. One of these fields is literature. In this study, it is aimed to introduce the technique of intermedia, to determine how it is used in literary texts and to examine its effect on literary texts. For this, the concepts of media and new media will be handled first. In this section, the etymology of the concept of media and its broad and narrow uses will be discussed. Then, the emergence of the term intermedia, the relationship and exchange of different media fields will be dealt with. After that, focusing on the meaning and scope of the term intermedia, how it is utilized in literary texts will be shown and different media elements will be determined based on some prominent works in Kurdish literature and how they are used will be explained. Within this framework, inter-media relations will be examined under three headings in the works named Bîra Qederê, Gerîneka Guernicayê, Belkî Îșev Binive, Şevekî Îstîsmar, Fîtnevîzyon, Tarantîno Bavê Min û Ez, Hêvî û Têkoşîn, Saturn, Pirça Winda, Cemîlê Nîgarkêş û Heft Qambihostên Dewletê. Firstly, the use of photography in novels and stories; secondly, the use of cinema and television in novels, stories and poetry, and in the third category, the mention of new media elements such as whatsapp, instagram, youtube, facebook, which are mostly included in our lives by the internet media, in the literary texts or their effects on the literary texts will be determined and analyzed in the context of the mentioned works. While doing this, the comparison method will be used. 


\section{Kurte}

Armanca vê xebatê danasîna teknîka navbermedyayiyê, tesbîtkirina bikaranîna wê ya di metnên edebî de û bandora wê ya li ser tekstên edebî ye. Ji bo vê pêşiyê em dê li ser têgehên medyayê û medyaya nû bisekinin. Di vê beşê de em dê li ser etîmolojiya têgeha medyayê û di wateya fireh û teng de bikaranînên wê bisekinin. Dû re dê temasî pêvajoya derketina têgeha navbermedyayiyê, têkiliyên navbermedyayî yên qadên cuda û danûstendinên wan bê kirin. Piştî vê, em dê zîqî ser wate û wergirtina nav xwe ya têgeha navbermedyayiyê bin û di metnên edebî de çawa ji navbermedyayiyê sûd tê girtin, ji çend berhemên ku di edebiyata Kurdî (Kurmancî) de derketine pêş hereket bikin û medyayên cuda di nava hev de çawa hatine bikaranîn nîşan bidin. Di vê çerçoweyê de berhemên bi navê Bîra Qederê, Gerîneka Guernicayê, Belkî Îşev Binive, Şevekî Îstîsmar, Fîtnevîzyon, Tarantîno Bavê Min û Ez, Hêvî û Têkoşîn, Saturn, Pirça Winda û Cemîlê Nîgarkêş û Heft Qambihostên Dewletê têkiliyên navbermedyayî di bin sê sernavan de hatine analîzkirin. Di serî de di roman û çîrokê de bikaranîna fotografan; ya duyem di helbest, çîrok û romanê de bikaranîna sînema û televîzyonê û di ya sisiyan de jî bêhtir hêmanên wekî whatsApp, instagram, youtube, facebook ku aîdî medyaya înternetê ku bandora wan ya li ser metnên edebî yan jî di metnên edebî de behsa wana çawa debas dibe, di berhemên navborî de dê ev xal bên tesbît û tehlîlkirin. Ji bo vê jî em dê ji teknîka berawirdkirinê sûd bigirin.

Bêjeyên Sereke: Medya, medyaya nû, navbermedyayî, metnên hîbrît, edebiyata Kurdî 


\section{Destpêk}

Huner jiyanê ji xwe re wekî çavkaniyekê bi kar tîne. Guherînên jiyanê jî bandorê li berhemên hunerî dikin. Edebiyata ku şaxeke hunerê ya geş e jî ji van guherînan para xwe hildide. Bi vî awayî jî em dikarin bibêjin edebiyat xwe ji paşdemayînê dûr dixe, xwe nû dike. Ne tenê edebiyatên netewên pêşdeçûyî, yên xwedî sazî û dezgeh in, wan guherînan dijîn; di edebiyatên kêmnetewan de jî bandora van guherînan xwe diyar dike. Di vî aliyî de gava em bala xwe bidin edebiyata Kurdî ya nûjen, em dikarin bibêjin ev edebiyat bi gelek kêmasî, astengî, qelsî û xetereyan re rûbirû ye. Pevajoya asîmîlasyon û otoasîmîlasyon, zext û zordariyên fermî yên polîtîk û psîkolojîk hem di jiyana rojane de bikaranîna zimanê Kurdî ${ }^{2}$ qels dike, ji nava jiyana rojane vedikişîne hem jî di xebatên entelektuelî de astengiyan derdixe. Ji ber van û gelek sedemên din, di xebatên hunerî de Kurdî hê jî xwe negîhandiye asteke baş. Lê li hember van pirsgirêkan jî hunermendên Kurd, di xebatên hunerî de bi ceribandina rê û rêbazên nû derdikevîn pêşiya hezkirên huner û edebiyatê. Ji van rêbazan yek jî di metnên edebî de bikaranîna rêbaza navbermedyayiyê (intermediality) ye.

Peyva medyayê di roja me de di wateya "çapemeniyê" de, ango di wateyeke teng de tê bikaranîn.Bi vê peyvê bêhtir rojname, kovar, televîzyon, radyo û hwd tên bîra mirov. Lê wekî ku em dê li jêrê li ser bisekinin jî̀, di rastiya xwe de medya xwedî wate û bandoreke firehtir e. Navbermedyayî jî ji vê peyvê tê çêkirin û têkiliyên medyayên cuda îşaret dike.Em di vê xebatê de dixwazin ewil li ser wate, cure û fonksiyonên medyayê bisekinin.Dû re navbermedyayiyê îzeh bikin û li ser têkiliyên navbermedyayî bisekinin. Piştî vê beșa teorîk, em dixwazin ji van zanînên teorîk hereket bikin û di van berheman de têkiliyên navbermedyayî nîșan bidin û îzeh bikin: Saturn ya Remezan Alan, Gerineka Guernicayê ya Yıldız Çakar, Fîtnevîzyon yaCîhan Yildirim, Hêvî û Têkoşîn ya Omîtê Mistefê, Belkî îşev binive ya Murat Bayram, Pirça Winda ya Mihemed Şarman, Şeveke Îstismar ya Omer Faruk Baran, Tarantîno Babê Min û Ez ya Şehmus Kurt, Cemîlê Nîgarkêş û Heft Qambihostên Dewletê ya Şener Ozmen.

\section{Medya û Medyaya Nû}

Peyva "medya”yê ji peyva latînî ya "medium"ê tê û derbasî zimanên Awrûpî dibe. Di Îngilîzî de di wateyên "orte”, "nîvek”, "weset”, "navgîn”, "amraz", "navbeynkar" de tê bikaranîn (Hony û İz, 1993). Lars Elleström jî koka peyvê digihîne peyva "medium"ê û dibêje di wateya "middle” (orte, navgîn), "interval” (nav, navbeyn) û "interplace" (navber) de tê bikaranîn (Elleström, 2010: 13). Gürsel Aytaç jî medyayê di wateya "navbeynkar"an pênase dike (2002: 1). Di xebatên qada ragihandinê de û di bikaranînên rojane de medya di wateyeke teng de derdikeve pêş; bi vê peyvê kovar, rojname û televîzyon zêdetir tê bîra mirovan. Kayaoğlu behsa wateya fireh ya medyayê dike. Bi pênaseke gelemperî medya, ji bo amraz û dorhêlên ku kêrî veşartin, bikaranîn û veguhestina agahiyan 
tê yan jî ji resmên çar hezar sal berê li dûwarên şikeftan hatine çêkirin bigirê heta înternetê, hemû qad, rê û rêbazên ku mirov ji bo ragihandinê bi kar tînin îfade dike (Kayaoğlu, 2009: 16-17). Ji resmên li ser dîwarên şikeftan heta înternetê pêşketinên di hezaran salan de pêk hatine li ber çavan in. Ev pêşketin jî dibin sedemên hinek dabeşkirinan di nava medyayan de. Faulstich medyayan li gor îmkanên wan di çar beşan de tasnîf dike. Medyayên di kategoriya yekem de cîh digirin hewceyî amrazekî navgîn nabînin. Ji bo vê kategoriyê cûreyên reqsê, telak, meddah, şano û rîtuelên ku bi alîkariya mirovan pêk tên (şaman û pêxember em dikarin bînin bîra xwe) mînak dide. Di kategoriya duyem de medyayên ku hewcedariya wan bi amrazên teknîkî ve hene cîh digirin. Ji bo vana jî her cure tekstên nivîskî û çapkirî yên wekî pirtûk, kovar, rojname, name, fotografan em dikarin mînak bidin. Medyayên di kategoriya sêyem de cîh digirin jî hem di hilberandin û hem jî di serfkirin (mezaxî) a wan de hewcedarî bi hêmanekî teknîkî heye. Radyo, televîzyon, fîlm, vîdeo, qasêt, CD, DVD û telefonên berikê em dikarin ji bo vê kategoriyê mînak bidin. Kategoriya çarem ku Faulstich paşê lê zêde dike jî ji medyayên dîîtal pêk tên. Înternet, e-posta, torên medyaya civakî jî em dikarin ji vê beşê re wekî mînak nîşan bidin (ji Faulstich veguhêzer Keleş û Can, 2016: 2-3). Wekî di kategorîzasyona Faulstich de jî diyar dibe, di dabeşkirina medyayan de teknîk û pêşketinên teknîkî derdikevin pêş.

Mirovatî merhele bi merhele pêş de çûye. Di qada medyayê de jî pêşketinên teknolojiyê, pencereyên nû vekirin û îmkanên nû afirandin. Bi taybet 1990 î de bi derketina înternetê ve medyaya dîîttal, sal bi sal bêhtir xwe nîşan da û di nava jiyanê de cîhê xwe girt. Di sedsala nozdemîn de telefon, telgraf, fotograf û sînema, di salên 1920an de radyo, salên 1950an de televîzyon û di salên 1970an de jî kompîter û salên 1990'i şûnde jî înternetê di jiyana me de cîhekî girîng îşqal kir û ev cîh roj bi roj jî zêdetir û firehtir dibe. Kompîtirên berê tenê ji bo ragihandina leşkerî bûn. Paşê îmkanên bikaranînê zêde bûn û di 1990 ŝ şûnde medyaya dîîtal derket pêş. Em dikarin van pêşketinan ji şemaya jêrê bişopînin: 


\section{Şema 1:}

\section{JI KU BER BI KU?}

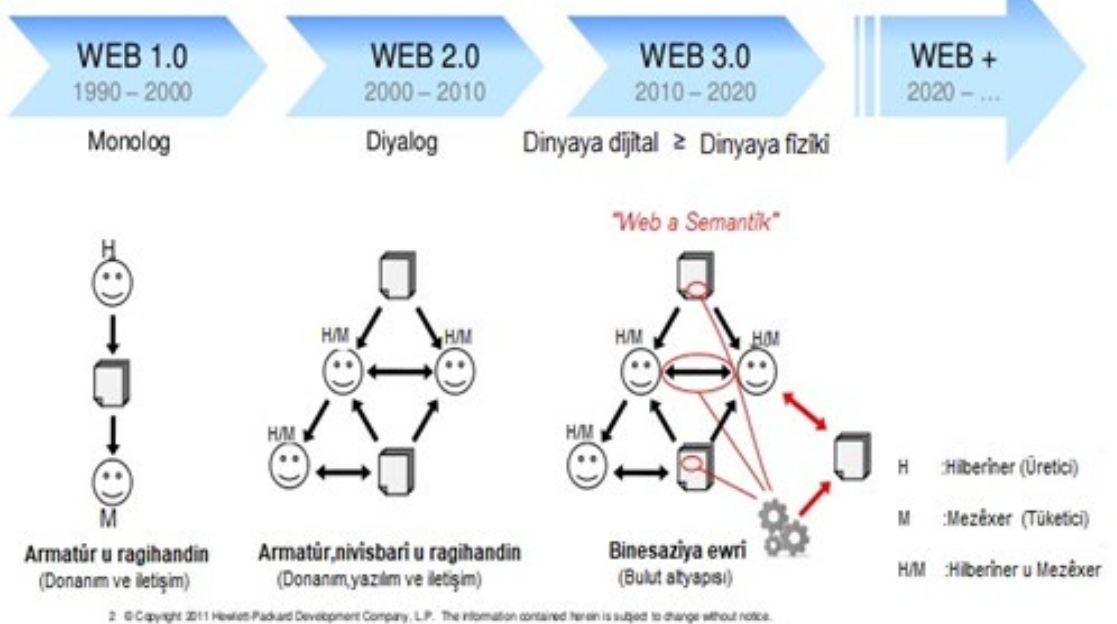

Bi vê şemaya³ jorê bi kurtasî pêşketinên tora înternetê hatiye îfadekirin. Wekî ji şablonê jî diyar e, di navbera salên 1990-2000an de web 1.0 ragihandineke yekalî pêk tîne û giran e. Di navbera salên 2000-2010an de înternet û îmkanên înternetê zêdetir dibe. Êdî têkiliyeke piralî dikare pêk bê û ji ragihandinê heta etîcaretê danûstandineke aktîf bi alîkariya înternetê pêk tê. Xêra serê vê pêşketina teknolojîk hûn dikarin ji kompîtirê heta telefona berikê, ji deriyê avahiyê heta kamerayên ewlehiyê, ji balefiran heta satalaytên fezayê di jiyanê de gelek tiștên ku çendîn sal berê bêîmkan dihate dîtin bi alîkariya vê teknolojiyê kontrol bikin. Ji televîzyona reş û spî me xwe gîhandiye îro ku di heman demê de bi sedan kes di heman ekranê de dikarin bi hev re biaxivin, hevdu bibînin. Ev medya êdî wekî "medyaya nû" tê binavkirin û ji binî ve dîîital e û wekî ku Canan û Bulduk jî îşaret dikin, îmkana jiyaneke dîjîtal dide însanan.Di tasnîfkirina medyaya klasîk û medyaya nûjen de însan dikare du gerdûnên cuda bibîne. Lewre medyaya klasîk de tv, radyo, muzîk, sînema, fotograf, kasêt; rojname, kovar, pirtûk, panoyên îlanê û reklaman cîh digirt. Lê di medyaya nû de sîteyên webê, APSS, e-mail, podcast, telefonên baqil, streaming vîdeo, blog, wiki, e-pirtûk, RSS Feeds, torên civakî, muzîk û weşanên bê navber cîh digirin. Di medyaya nû de dîjîtalî sereke ye (Canatak û Bulduk, 2019: r.73-75).

Di tora Web 3.oê de ev teknolojî pêşdetir diçe û dîîitalîzekirina jiyanê zêdetir derdikeve pêş. Lê ev pêşketin û guherandinên teknolojîk, di her qada jiyanê de xwedî bandor e. Dîsîplînên cuda ji van pêşketinan îstifade dikin. Di xebatên fîzîk, kîmya û xebatên fezayî û molekulerî de jî û di endezyarî, coxrafya, 
dîrok û arkeolojiyê de jî ji vê teknolojiyê sûd tê girtin. Di heman demê de di xebatên hunerî de jî hunermend ji van pêş̧ketinên teknolojiyê sûd digirin. Wekî mînak em dikarin behsa sînemayê bikin. Êdî qeydkirin û belavkirina fîlman hêsantir û zûtir pêk tê. Di heman demê de pêşketinên Web 2.oê de di fîlman de em axaftin û nivîsên li ser facebook, e-mail û peyamên whatsAppê jî dikarin bibînin (Canan û Bulduk, 2019: 68-70). Axaftinên whatsAppê bi form û uslûba xwe di romanekê de dikare cîh bigire yan jî lînkek ji bo çavkaniyekî nîşan bide, ji aliyê nivîskar ve dikare di çîrok yan jî di romanekê de were dayîn û di formên epirtûkên van berheman de xwendevan dikarin pêlî lînkê bikin û bi alîkariya înternetê ji pirtûkekê derbasî malpereke dokumanter yan jî malpereke muzîkê bin. Yan jî bi sedan, bi hezaran e-pirtûkan bi alîkariya tabletekê dikarin di berika xwe de bigerînin. Bi vî awayî tekiliyên medyayên cuda jî derdikevin ber me.Ji ber vê divê em li ser "navbermedyayî"yê jî bisekinin.

\section{Navbermedyayî yan jî di hunerê de melezbûn}

Navbermedyayî ango întermedîalîty peyveke hevedudanî ye û ji peyvên "înter" û "medîa"yê pêk tê.Ersel Kayaoğlu dibêje navbermedyayî rêbazeke estetîkî ye ku hunermend û nivîskar ji bo hevbandoriya di navbera medyayên cuda de ji vê rêbazê îstifade dikin. Rêbaz, mijar, formên vegotinê, bilêvkirinên ku aîlî medyayeke diyar in, di medyayeke din de jê sûd bê girtin yan jî ji xwe re bike mijar, bi vî awayî ew medya di nava medyaya din de dihele, cîh digire yan jî veşartî be jî̀, xwedî bandorekê dibe. Bi vî awayî jî medyaya ku ji medyayên din sûd digire, sînorê xwe fireh dike, wate û taybetiyên nû li wê zêde dike. Bi vî awayî, di navbera du medyayên ku ji aliyê konvansiyonelî ve cudabûna wan hatiye qebûlkirin de danûstandineke ku dikare bê îspatkirin û ferqkirin hebe, li wira navbermedyayî pêk hatiye (2009: 9). Gabriele Rippl jî pênaseyeke nêzîkî vê dike; "teknîk, amraz û rêbazên vegotinê yên medyayên cuda di medyayekê de bê teqlîtkirin, bê bikaranîn yan jî bibe mijar" vê wekî navbermedyayî pênase dike (ji Rippl veguhestin Canatak û Bulduk, 2019: 95).Navbermedyayî tiştekî nû nîn e, lê ji peyva navbermetnanî (intertextuality) hatiye hereketkirin û terma navbermedyayî derketiye holê.Di salên 1990an vir ve di qada rexneya edebî de wekî rêbazeke nû tê pêjirandin.Lê bingeha vê rêbazê ji salên 1950an dest pê dike. Di wan salan de muzîk, hunerên estetîk, fîlm, tiyatro û medyayên cuda bi hev re di nava têkiliyên fireh de ne. 1965an de Dick Higgins terma "intermedia"yê bi kar tîne. Higgins bi sernavê "intermedia"yê manîfestoyekê belav dike û dibêje min ev peyv ji helbestvanê Îngilîz Samuel Taylor Coleridge (1772-1834) girtiye. Peyvê ji bo berhemên hunerê yên ku di nava cureyeke diyarkirî de cih nagire û ji hunerên cuda sûd digire re bi kar tîne, ango ji bo berhemên hunerî yên "hîbrît" (hybrid) an jî "melez" (Canatak û Bulduk, 2019: 95). Ersel Kayaoğlu navbermedyayîyê bi van gotinan dinasîne:

Navbermedyayî wekî rêbazek estetîk a ku ji aliyê hunermend û nivîskaran ve ji bo hevbandoriya di navbera medyayên cuda tê bikaranîn, dikarê bê terîfkirin. Rêbaz, mijar, şiklên vegotinê hwd yên 
aîdî medyayekî ne ku di medyayeke din de hat bikaranîn yan jî teqlîtkirin, ev rêbaz, mijar, forma vegotinê û uslûba vê medyaya biyanî bi şiklekî, daxilî wê medyaya ku vana teqlît dike yan jî xwe dişibîne wê. Bi vî awayî wê çîrok yan jî wê medyaya ku vê ji xwe re dike mijar re îmkana firehkirina sînorên wê medyayê, dewlemendkirina wate û taybetîyan dikarin derkevin holê. Bi vê gotinê ve girêdayî, di wateya gelemperî em dikarin bibêjin navbermedyayî, herî kêm du îfade yan jî medyayên ragihandinê yên ku lihevkirinî (konvansiyonel) cudabûna wan tê pejirandin di berhemeke hunerî de bi hev re cih bigirin û îmkana ferqkirin yan jî îspatkirina vê hebûnê îfade dike ${ }^{4}$ (Kayaoğlu, 2009: 9).

M. Osman Toklu jî dibêje jê sûdgirtina amraza medyaya ku tê îşaretkirin yan jî pê re têkilî tê danîn di nava medyayeke din de ji nû ve çêkirin, yek ku mijara yeka din pêk bîne, ev jî navbermedyayî ye (Toklu, 2008: 245). Fatih Arslan jî terîfeke nêzîkî Kayaoğlu û Toklu dike (Arslan, 2016: 52). Ji van gotinên jorê derdikeve holê ku di qadên cuda yên wekî edebiyat, muzîk, mîmarî, peykersazî, resim û sînema, rojname, kovar û televîzyon û hwd vana medyayên cuda ne. Vana xwedî rê, rêbaz û uslûbên cuda ne. Lê hemû jî formekî îfadekirina hest, raman û biryarên mirov in. Ger ji van medyayên cuda ji aliyê mijar, forma vegotinê, uslûb yan jî rêbazê ve ji hevdu sûd bigirin yan jî vana ji xwe re bikin mijar, wê gavê li wira têkiliyeke navbermedyayî pêk tê.

Di qada rexneya edebî de cara yekem A. Hansen-Löve di sala 1983an de vê rêbazê bi kar tîne (Kayaoğlu, 2009: 50-51 û 60) û bi taybet jî piştî salên 1990î, hejmara kesên ku li ser vê rêbazê disekinin zêde dibin. Ji vana yek jî Werner Wolf e û navbermedyayiyê di du beşan de dabeş dike: navbermedyayî ya vekirî û navbermedyayî ya veşartî (Kayaoğlu, 2009: 64) Mînak, di çîrokên Murat Bayram de rasterast fotograf hene û ev navbermedyayiyeke vekirî ye; di romana Navê Min Sor e ya Orhan Pamuk de jî nivîskar mînyatur û resmê dike xizmeta edebiyatê û navbermedyayiyek veşartî tê bikaranîn.

Wekî Marshall McLuhan jî dibêje, "Feraseta dema nû ya însanê tîpografîk sînematîk, rêzeyî û wêneyî ye” (McLuhan, 2001: 336). Di vê peywendê de em jî dixwazin di çend berhemên Kurdî ya Kurmancî de li ser têkiliyên navbermedyayî û bi taybet jî têkiliya edebiyat û medyayên dîtbarî tespît, analîz û şîrove bikin.

\section{Di Edebiyata Kurdî ya Kurmancî De Ji Bo Têkiliyên Navbermedyayî Çend Mînak \\ Di vê beşê de em dixwazin li ser çend berhemên Kurmancî mijara xwe firehtir û kûrtir bikolin. Vê jî dixwazin di sê sernavan de dabeş bikin. Bi taybet em dixwazin di du sernavan de têkiliya fotograf, sinema û televîzyonê bi berhemên edebî re nîşan bidin. Di sernavê sisiyan de jî di berhemên edebî de em dê li ser amraz û amûrên medyayên înternetê, ragihandinê û bikaranîna wan bisekinin.}

4Di vê xebatê de veguhêzên wergera beșên ji pirtûkên bi Kurdî nîn in, me wergerandine. 


\subsection{Di roman û çîrokan de fotograf û resim}

Wekî li jorê jî me îşaret kir, di edebiyata Kurdî (Kurmancî) de, bi taybet di roman û çîrokan de nivîskaran ji têkiliyên navbermedyayî sûd girtine. Medyaya ku ewil em dê li ser bisekinin fotograf e. Ji lewre fotograf, di sedsala nozdemîn de derdikeve holê û bi xwe re pêşketinên nû yên wekî sinema û televîzyonê jî diafirîne.

Di vê xalê de berhema yekem ya ku em dixwazin li ser bisekinin romana Mehmed Uzun ya bi navê Bîra Qederê ye. Di romanê de jiyana Celadet Alî Bedirxan hatiye vegotin ji ber vê romaneke biyografîk e û taybetiyeke romanên biyografîk jî ji belgeyan sûdgirtin e. Uzun di dîroka 23 Îlon 1995an de hevpeyvîna bi Seyidxan Kurij re pêk aniye de li ser Bîra Qederê disekine û cureya romanê bi van gotinan tîne ziman: "Roman li ser jiyana ronakbîrê kurd Celadet Alî Bedir-Xan e. [...] Ew jî, mîna hin romanên min ên din, hem romaneke tarîxî û biyografik e, hem jî, heta qadekê, didaktik e" (Uzun, 1996: 107). Murathan Mungan jî dibêje, "Gava ko em dixwazin li ser çîroka jiyanê tiştekî binivîsin, hingê em serî li alîkariya fotografan didin" (Mungan, 2008: 107). Di romanên biyografîk de cîhdayîna fotografan, di vê wateyê de ye ku roman xwe dispêre jiyan û bûyerên rastî. Wekî ku Mustafa Apaydın (2002: 464) jî îşaret dike, di romanên bîyografîk de bikaranîna fotografan, hem ji bo mijara romanê dispêre rastiyê hem jî leheng forma romana kevneşop belav dike, dişikîne. Bi vî awayî ku em li romana Bîra Qederê dinihêrin, di romanê de jî ev herdu xal li ber çavan e. Ji lewre roman bingeha xwe û bi leheng û serlehengê xwe ve, xwe dispêre rastiyê, bi piranî. Di romanê de Mehmed Uzun rasterast fotografan bi kar nayîne. Lê bi şayesandinê ew radixin ber xwendevanan. Hê di beşa destpêkê de dibêje,

Ji çilî zêdetir resim. Ji çilî zêdet kurte-demên bihurî û qeyîtkirî. Li vir û li wir. Hin ji wan bi hunermendiya fotografkêşên hoste hatine kişandin. Di hinan de jî ne huner û ne jî hostahî heye, ew bi tenê ji bo îspatkirina jiyan, wext û demên bihurî hatine veşartin. Hemû jî bi rengên reş û spî ne. [...] Bêguman çeşnên reș û spî jî tê de ne; hin vekirî ne, hin jî girtî. Hinên wan portre ne, nîşana jiyana Celadet Begê ne. Di hinan de jî gelek kes bi hev re ne, îspata yekbûn, hevgirtin, hevkarî, dostî, merivahî û biratiyê ne. Hin jî bi tenê bergeh in, cîh û warên ku jiyanek tê re bihuriye (Uzun, 2002: 15).

Ji van gotinan jî diyar e ku hem di aliyê naverokê de hem jî di aliyê şeklî ve derheqê fotografan de agahiyan dide. Her çiqas di beşa destpêkê de vebêjer behsa çilî zêdetir fotografan bike jî, ji vana şanzdeh heb derdikevin pêş. Xêncî beşa destpêkê, şandeh beş bi hêjmara fotografan ve hatine dabeşkirin û "Fotograf 1.", "Fotograf 2.", "Fotograf 3." û wisa dewam dike, piștî fotografê 15., beşa dawî ango fotografa 16. jî wekî “Fotografa Dawî” cîh digire. Lê xêncî vana, di beşa yekem de jî fotografek heye û di wir de Rûşen Xanim, li erdê rûdinê û fotografekî dide destê xwe. Paşê bi texmînî dibêje ev fotograf aîdî sala 1926an e û dest bi tasvîra fotografê Celadet Alî Bedirxan dike. Ev tasvîr qasî nîv rûpelî 
didome (Uzun, 2002: 15). Di beşa yekem de vebêjer li ser giringiya fotografan disekine. Rûşen Xanim dibêje, "Kî dê niha pêşî li van resiman binihêre û paşê wan bîne ziman? Kengê ev fotograf ê dest bi peyivînê bikin?” (Uzun, 2002: 16). Em dikarin van hevokan weke "şîfreya vegotinê" binav bikin. Ji ber ku piştî van gotinan beşên ku "fotograf û tasvîrkirina wan" dest pê dike. Beşa yekem de hevoka yekem ev e: "Herwekî ku hatiye gotin, meriv pêşî dibîne û dinihêre, paşê jî dipeyive û dibêje5" (Uzun, 2002: 17). Em dikarin vê hevokê jî bi hevoka Rûşen Xanimê ve girêdin û şîrove bikin. Di romanê de jî berê peyva "fotograf"ê derdikeve pêşiya xwendevanan.Yanî berê "dîtin û nihêrîn" heye.Em fotografan dibînin.Paşê jî "peyivîn” û şîrove. Di romanê de bi danasîn û tasvîrên fotografan mekân, kes û tiştên ku ketina çargoşeya fotografê em ji wan agahdar dibin. Paşê bi şîroveyan, perspektîfa pêşiya xwendevanan firehtir dibe.Wekî rûyê bîrê ewil dixûyê, paşê em xwe çiqas lê zîq bikin, tiştên em dibînin zêdetir dibin.Vebêjer jî hêdî hêdî, li ser fotografê hûr dibe û ber bi xalên piçûk ve gotinên xwe fireh dike.Her firehbûn tê wateya firehkirina agahiyan.Wekî kolandina bîrê, vebêjer jî fotografan dikole.Ev forma vegotinê, ango bi şayesandinê wêne û dîmenan di hunera Awrûpayê bi têgeha "ekhprasis" tê îfadekirin.Peyv di Yewnanî de ji peyvên ek û phrazienê pêk tê û di wateya "îlankirin", "binavkirina tiştan" de ye. Bi demê re wateya wê guheriye û ji bo berhemên hunerên dîtbarî yên ku di nav metnên edebî de tên bikaranîn, hatiye bikaranîn (Uzundemir, 2010: 29). Nazmi Ağıl jî dibêje ev peyv di wateya "bi dengê bilind, rasterast gotin", "bi hemû hurgiliyên ve gotin"ê de ye (Ağıl, 2015: 13-14). Lê herdu jî di vê xalê de digîhin hev ku "ekfrasis" ji bo tasvîrkirina berhemên dîtbarî, ji afîş û fîlman bigire heta tasvîrên di berhemên edebî de, ji bo hemûyan tê bikaranîn. Ev têgeh tam jî tiştê ku Mehmed Uzun dike, îfade dike: "Fotograf mirî ne; bêzar û bêziman, bêdeng û bêpejn in. Kesê ku li wan dinihêre, li gora xwe, jiyanekê û dengekî dide wan" (Uzun, 2002: 211). Vebêjerê Mehmed Uzun jî berdevkiya van dîmenan dike, bi tasvîrên xwe, bi peyvên xwe, dîmenan li ber çavên xwendevanan şênber dike. Wekî me li jorê jî îşaret kir, ji vê formê re dibêjin navbermedyayî ya veşartî. Ji lewre fotograf rasterast di pirtûkê de tunin. Lê dema me li ser hebûn û tunebûna fotografan lêkolîn kir, me dît ku ew wêneyên ku di romana Mehmed Uzun de cîh digirin, piraniya wan hene, dibe ku hemû jî hebin. Ji lewre em dizanin ku Mehmed Uzun ji bo vê romanê hem rasterast ji malbat û arşîva malbata Celadet Alî Bedirxan û hem jî ji kesên ku bi malbata Bedirxanî re bûne sûd girtiye. Ji bo fotografan em dikarin mînakekî bidin. Di romanê de ji bo "fotografa 6." tê gotin ku ji aliyê Major E. W. Noel ve hatiye kişandin û fotograf wiha hatiye tasvîrkirin:

Li ser fotoyê du kesên nas hene; Celadet û birayê wî Kamuran Alî Bedirxan.Herdu li pê, li kêleka hevûdu, li ber stûneke stûr a şaneşînekê sekinîne. Dar û berên bexçe bergeha fotografê dixemilînin.Celadet li kamerayê, Kamuran li aliyê bexçê dinihêre.Herdu jî bi simbêl, bi kincên siwaran, lê bi qrawat in.Porê

\footnotetext{
5 Ev gotina Mehmed Uzun, vê gotina John Berger tîna bîra mirov: "Dîtin beriya axaftinê pêk hatiye. Zarok beriya dest bi axaftinê bike, hînî dîtin û nasînê dibe" (Berger, 2009: 7).
} 
herduya jî, bi paş de, şehkirî ye.Celadet bi qasî çend tiliyan ji Kamuran dirêjtir e û bi qasî çend tiliyan li pêş wî rawestiyaye.Şiveke siwaran di destê Celadet de ye. Kamuran, dest ber bi jêr, bi awayekî serbest sekiniye. Ji rawestana herduyan dixuye ku Celadet bêtir xwedî berpirsiyarî û gotin e. Herdu bi rêz û rêzdarî sekinîne. Awirên wan cîddî, nêrîna wan kûr e.

Kincên wan li xwe kirine, nû ne û ji kincên siwar, rêwî, nêçîrvan û seyidvanên îngilîzan in. Çaketên herduyan jî, ji navtengê, bi kemerekê, hatine şidandin. Pantolon ji jor fireh, ber bi delingan teng in.Kincên herduyan jî mîna hev in.Kinc ne yên mintiqê ne, ne yên welatê Osmanîne jî. Kincên wan yên ewrûpiyan in. Yanê du kurdên ji maleke navdar a kurdî, bi cil û bergên ewrûpayî, li welatê bav û kalan in. Du Stemboliyên kurd li welatê kurdan in (Uzun, 2002: 128).

Fotografa ku bi van gotinan hatiye şayesandin û di pirtûka Noel (2014) de cîh digire ev e:

\section{Fotograf 1:}

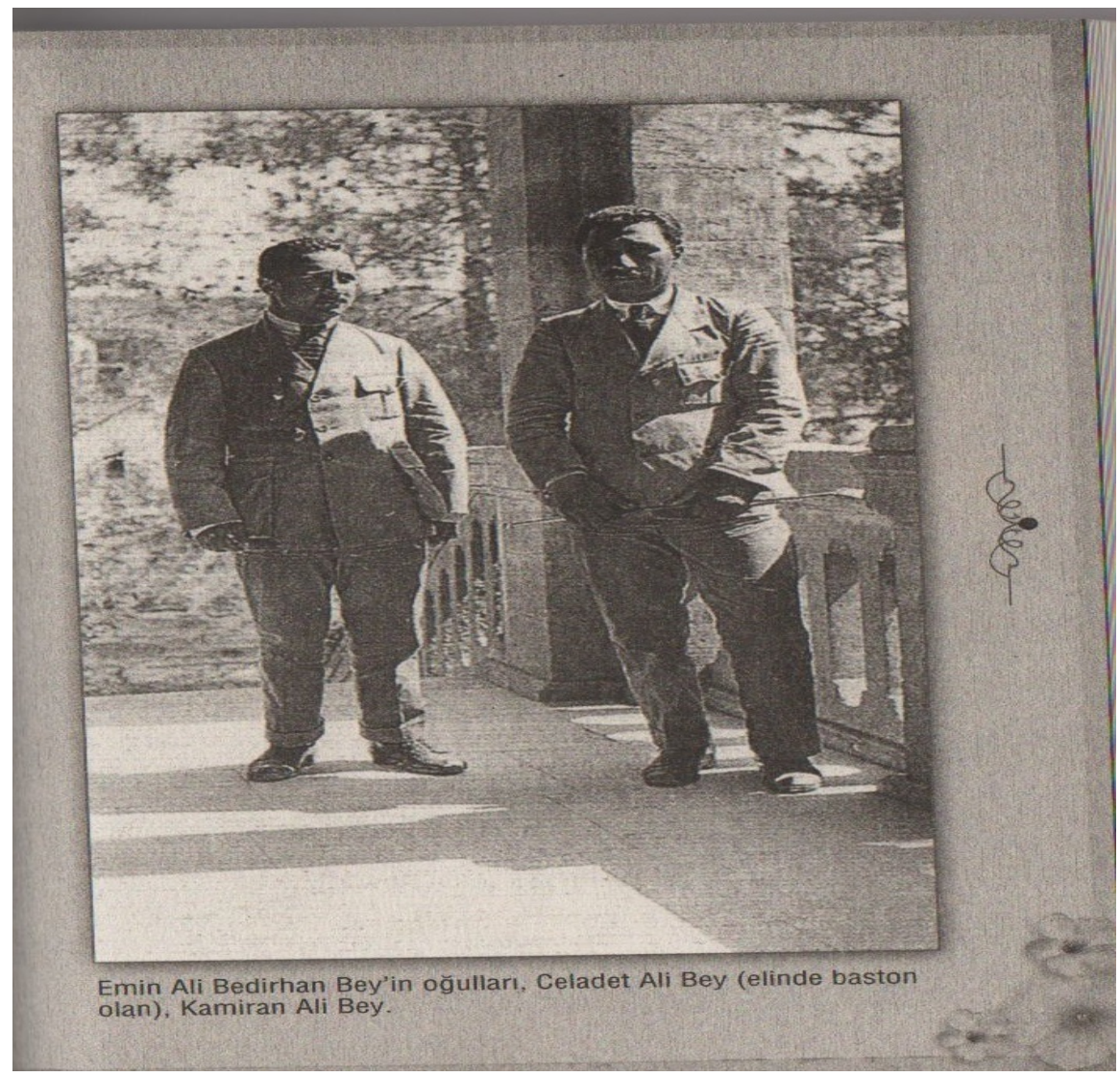


Xêncî vê dîmenê, di romanê de fotografên ku Mehmed Uzun şayesandiye çend heb di berhemên cuda de derketin ber me. Ji vana Cizîra Botanlı Bedirhaniler ya Malmîsanij (2000), Bajarê Cizîra Botan û Hunera Mîr Bedirxan ya Konê Reş (2013), Günlük Notlar (1922-1925) ya Celadet (1997), Defter-i Â'malım ya Mehmed Salih Bedirhan (1998), Dotmam ya Rewşen Bedirxan (2009) û Albuma Bedirxaniyan ya Hemîd Ebubekir Bedirxan (2013) me dîtin û em dikarin bibêjin ku îhtimalek mezin Mehmed Uzun jî ji bo Bîra Qederê ji van fotografan sûd girtiye ${ }^{6}$.

Taybetiyeke din ya romana Bîra Qederê jî ew e ku di nava pirtûkê de li ser hunera fotografê û fotokêșan jî agahiyan dide. Mînak, beşa "Fotograf 2" de behsa fotokêșên Kadikoyê dike û dibêje,

Li hemû Kadikoyê du fotografkêşên hoste hene; Th. Servanis û R. Xendamian.Yê yekemîn cihû, yê duwemîn ermen e. Mîna her tiştê Kadikoyê, fotografkêşê jî di destê endamên miletên têkel de ye. Fotograf û fotokêşî, hem li Stembol û Kadikoyê hem jî di nav hemû tixûbên dewleta Osmanî de, nav û tiștên nû ne. Nav û tiştên nû ku pir bala xelkê, lê bi taybetî jî pir bala giregir, dewlemend û paşayên dewleta Osmanî dikişîne. Berê lewhe û wêne hebûn, niha jî fotograf. Berê wênekêş û resam radihiştin pênûs û firçan û li ser kaxiz û cawan bi rojan, mehan, dixebitîn da ku resimek, wêneyek bînin pê.Lê niha fotokêş, bi alîkariya makina xwe, di nav kêliyekê de, xebateke demeke dirêj tîne pê.Meriv, rû, çav, dev, nihêrîn, awir di nav bîskekê de direșin ser kaxizên taybetî yên spî û dibin nemir (Uzun, 2002: 35).

Di rûpela dewama vê de li ser hunera fotografê û fotokêșiyê disekine û felsefe û sosyolojiya fotografê şîrove dike. Beşa "Fotograf 3 " de dibêje di binê fotografê sêyemîn de navê Abdullah Freres heye û nêzîkî du rûpelan li ser Abdullah Freres û fotokêșên navdar yên Stembolê disekine (Uzun, 2002: 67). Di beşa "Fotograf 4" de behsa "Apollon Fotografhanesi” ya li ser Cadde-i Kebîr dike (Uzun, 2002: 89). Di "fotograf 6"an de careke din li ser giringiya fotografê disekine (Uzun, 2002: 127) û di beşa “Fotograf 10"an de jî behsa albuma Mezîyetê ya xwîşka Celadet dike (Uzun, 2002: 218). Ev hemû jî nîşan didin ku nivîskar pir bi zanebûyî ji bo romana xwe ev teknîk bi kar aniye û bi vî awayî jî di romanûsiya Kurdî de tiştekî nû ceribandiye.

Berhemeke wêjeyî ya ku ji alîyê navbermedyayî ve em dixwazin li ser bisekinin Belkî îşev Binive ya Murat Bayram e. Şerê ku li çend bajêr û bajarokan di Tîrmeha 2015an de dest pê kiribû, bi xwe re gelek bûyerên trajîk jî anî holê. Wekî rojnamevanekî, nivîskar jî li ser van bûyeran û piştî ku bûyer qewimîn, çîrokên xwe organîze dike. Berhem pirtûkek ya çîrokan e û tê de fotograf û nivîs bi hev re ne. Ango wekî di Bîra Qederê de navbermedyayî veşartî nîn e, navbermedyayîyeke vekirî di vê pirtûkê de hatiye bikaranîn. Ji lewre çîrok bi

${ }^{6}$ Helbet dema em viya dibêjin, qesta me berhem nîn in, fotograf in û piraniya wan piştî romana Uzun hatine çapkirin. Lê fotograf di arşivên cuda de hebûn û îhtimal tune ku Mehmed Uzun xwe negîhandibe van fotografan. 
fotografan ve hatine çapkirin. Bi vî awayî nivîskar ji bo naveroka berhema xwe ji şahidiya fotografan sûd girtiye. Fotografan, bûyerên bûne mijara çîrokan bi dîmenan piştrast kirine. Di pirtûkê de bîst û pênc çîrok û bîst û pênc fotograf hene. Hemû fotograf reş û spî ne. Susan Sontag dibêje, "Fotografek, îspata tiştekî diyar e ku qewimiye" (Sontag, 2008: 22). Di vê peywendê de em dikarin bibêjin fotografên Bayram jî ji bo naveroka çîrokan û di heman demî de jî ji bo wan bûyerên ku gelek taxên bajêr û bajarokan kavil kirin, di asta îspatê de ne. Yan jî bi gotina Pierre Nora (2006), her fotografek ji roja me û pêşerojê re mekanê hafizayê ye û kurtedemekî di nava xwe de dihewîne û wê nemir dike.

Sosan Sontag li ser fotograf û rastiyê disekine û dibêje, "Ku fotograf û veguhêzan wekî perçeyên rastiyê bên hildan, ew dê ji vegotinên edebî yên direj resentir (orîîinaltir) bixûyin (Sontag, 2008: 94)." Di çîrokên Bayram de jî em dikarin bibêjin "edebiyat" bi vî awayî, di binê bandora fotografan de ye û hinek caran ji edebiyatê zêdetir fotograf derdikevin pêş. Em dikarin vê xalê wekî kêmasiya pirtûkê binirxînin. Ji lewre armanc fotoalbum nîn e, edebiyat e. Lê bi vî şiklî foto zêde derdikevin pêş. Ji bo ku têkiliya navbermedyayî pêk were, divê medyayek di nava medyaya din de bihele, jê re bibe alîkar, lê dema em dixwînin, bibînin û fehm bikin ku kîjan medya di nava kîjanî de heliyaye, kîjan ji kîjanî re dibe alîkar, divê em bi rehetî ji vê têbigîhin.

Ji bo mijara me berhema sêyem ya ku em dê li ser bisekinin Şeveke Îstismar ya Omer Faruk Baran e û ji bo têkiliya fotograf û edebiyatê mînakan dihewîne. Di pirtûkê de pênc fotograf hene û ev jî wêneyên flû ne. Di pirtûkê de leheng dermanên xwe dixwe û dibêje ez herkesî wekî jin dibînim (Baran, 2019: 32-33). Ango karakterekî nexweş heye li ber me û ji ber vê jî em dikarin van fotografên flû bi tevliheviya hişê wî ve girêdin. Hemû jî bi naveroka pirtûkê re têkildar in. Ji fotografan di sê heban de dîmen ji yên din bêhtir zelal in. Di fotografa duyem de ji lêvên boyaxkirî, neynikên dirêj diyar e ku dîmenê jinekê ye. Tenê devê wê û tiliyên we yên ku di nava wan de cixarek ya bi dûman heye. Serlehengî vê fotografê bi sernavê "Cixareya Tehranê" di Instagrama xwe de parve kiriye. Hevalê wî Sûrettîn jî keçikê nas dike û derbarê wê de ji serleheng pirsan dipirse. Fotografa din îlana maçekî ye ku li ser kaxizê spî bi Tirkî "Maça Galatasaray û Beşiktaşê 5 TL” dinivîse. Dîmenê din de lênûskek dixuyê ku di çîrokê de, hevalê serleheng deftera xwe derdixe û helbestekî dinivîse. Dîmena çarem de rûpeleke lênûskê ku tije nivîs e heye û ev jî helbesta hevalê serleheng Înan e ku li ser îlhama xwe ya wê êvarê ya li kafeyê nivîsiye. Dîmena dawî jî ya afîşeke li ser panoyeke kolanê ye. Li ser afîşê li hember tundiyê gotineke Tirkî heye: "Kadına şiddet insanlığa ihanettir." Di dîmenê de kefa destekî jî heye ku di wateya "bisekine" de ye. Ev wêneyên pirtûkê, rastiya jiyana bajêrî û nûjen radixe ber me. Ji lewre bajêrên nû de jiyan bi îmajan ve hatiye dagirkirin. Dîmen, ji gotinê zêdetir in.Ji axaftinê zêdetir bi îmajan peyam tên dayîn. Sontag dibêje "Civakên endustriyê hemwelatiyên xwe dikin muptelayê dîmenan; ev, şiklê qilêrîbûna hiş e ku nayê astengkirin" (Sontag, 2008: 40). Em dikarin bibêjin Baran jî bala me dikişîne ser vê desthilatdariya dîmenan. 
Berhema din ku em dê li ser bisekinin û têkiliya edebiyat û resmê nîșan bidin, pirtûka Yıldız Çakar ya bi navê Gerîneka Guernicayê yê. Dema em ji bo têkiliyên navbermedyayî berê xwe bidin vê pirtûkê, divê em di serî de li ser navê pirtûkê bisekinin. Di şerê navxweyî yê Îspanyayê de serokê Îspanyayê Franko, ji Almanan alîkarî dixwaze û balefirên Almanan bajêroka ku di destên çekdarên mixalif û çepgir de ye bi bombardimaneke giran ve kavil dikin (Lynton, 1982: 192). Picasso, vê hovîtiyê, vê qirkirina li hember hemû zindiyan û xwezayê bi formeke nû dikişîne ser tûalê.Xwendevanên ku vê çîroka hovîtiyê û tabloyê bizanibin, dê hê bi dîtin û xwendina navê pirtûkê re tabloya Picasso bînin bîra xwe.Ango dê metna edebî, berhemeke hunera dîtbarî bîne bîra wan.Ji vê cuda, di nava pirtûkê de jî vebêjer dê têkiliya naveroka pirtûkê û tabloya Picasso jî îfade bike.Hê di destpêka romanê de vebêjer di televîzyona vekirî de sehneyeke hovane dibîne û dibêje, "Jinek nîvtazî di nava toz û dûmana barûdê de bi zorê gavên xwe diavêt. Eniya wê ya doq, porê wê yê xelek xelekî û ew xêliya sor î li gerdena wê daliqandî, wek tabloyeke nîvcomayî dixuya" (Çakar, 2016: 11). Ev îbareya "tabloya nîvcomayî" de peyva "tablo"yê bi zelalî medyayeke din tîne bîra mirov. Ne tenê ev, di rûpela duyem ya romanê (ango r. 12) de carekî dîsa peyva "tablo"yê derbas dibe û di vê bêşê de sahneyeke wehşetê hatiye şayesandin:

Du gavan ji cama televîzyonê dûr ketim. Jinika di hundirê televîzyonê de hîn li ser lingan bû.Dixwest bimeşe.Rûyê wê yê spîçolkî, serê wê yê berjêr û gavên wê yê sewsî, rîtma dilê min hinekî din zêde kiribû. Cesedên li ber lingên wê, mil û pîyên ji hev ketî, mejiyên parçe parçe, çavên rijiyayî, zarokên ku bûne du felqe, qazaxên rîs, solên naylon, wêneyên şewitî ku ji malan pengizî ne û li kitêbên rengo rengo dev xistibûn axê. Xwîna reş, kincên li cesedan, darên şewîtî, gustîlên di tiliyan de û niviştên li ser pêsîran weke ku ji tabloyekê fêdî dikirin (Çakar, 2016: 12).

Bi dû van hevokan re vebêjer rasterast navê Picasso tîne zimên: "Ax, Picasso, ev ne Guernica ye! Ji cama televîzyonê, tabloyeke sawdar hemû mewcûdiyeta xwe girtibû û hatibû nava malê" (Çakar, 2016: 12). Di şayesandina paragrafa jorê û dîmenên tabloya Picasso û behskirina navê resam û tabloya wî, têkiliya ku di navê pirtûkê dest pê dike û heta naveroka wî didome. Di çend mînakên din de jî ev têkiliya navbermedyayî dewam dike (2016: 73). Di dewama mijarê de jî dibêje, "Ax Picasso, ka firça te?! Xwezî te jî bizanîbûya ku xwîn li vir gelekî erzan e!” (Çakar, 2016: 75). û bi van gotinan em dibînin ku bûyer û kuştinên li ser axa Kurdistanê bi riya tabloya Picasso, bi hovîtiya Îspanyayê ve tê girêdan yan jî bi vê ve tê şîrovekirin. Bi vî awayî jî çawa Picasso vê hovîtiyê bi hunera xwe ve dike nemir û ji pêlên jibîrkirinê rizgar dike; Çakar jî bi berhema xwe hovîtiyên di jiyana xwe de bîhîstiye, dîtiye û xwendiye, bi alîkariya romana xwe dike gerdûna hunerê û bi alîkariya hunera xwe wan ji pêlên jibîrkirin û windabûnê diparêze.

Berhema dawî ya ku em dê li ser bisekinin çîroka Şener Ozmenî ya bi sernavê “\#jinikaciwanabitenê" ye. Ev çîrok di pirtûka wî ya bi navê Cemîlê 
Nîgarkêş û Heft Qambihostên Dewletê de cîh digire. Di xebata Ozmenî de hê di navê pirtûkê de em têkiliya navbermedyayî dibînin. Lewre peyva "nîgarkêş" di wateya "ressam" de ye û hunera resimê tîne bîra me û bi vê bibîrxistînê jî têkiliya navbermedyayî pêk tê. Lê em dê bi taybet berê xwe bidin çîroka bi sernavê “\#jinikaciwanabitenê".Di çîrokê de serleheng û hevsera wî pev çûne û hevsera wî ji malê veqetiyaye. Di dema pevçûna wan de serleheng bi kulma xwe li derî dixe û qul dike. Ev qul di nava demê de xwe bi xwe fireh dibe. Serleheng naxwaze vê qulê bibîne. Ji ber vê jî, derî ji cîh derdixe û dibe şaneşînê. Lê dû re paş ve tîne. Lê qula li ser derî derbasî dîwarê salonê dibe û firehtir dibe. Leheng bi "ala rengîn" dixwaze binixumîne.Lê nabe û ji hostayekî alîkariyê dixwaze. Lê pêşniyara hoste jî wî sar dike. Dîwar di halê xwe de dihêle, lê rojekî dengekî cuda dibihîze û tê dibîne ku yekî xerîb di nava malê de ye. Ev, hatiye serleheng bibe cîhekî. Serleheng hew dibîne ku li cîhekî xerib e û li ber wî li ser qenepekî jineke çîprût dirêjkiri ye. Ev jina efsûnî, wisa tê şayesandin ku em têdigihîin ku ew dîmeneke ji tabloya Tiziano Vecellio (1490-1576) ya bi navê Venusa Urbîno (Venus of Urbino) ku di sala 1538an de xilas bûye. Şayesandina wê sahneyê di çîrokê de bi van gotinan cîh digire:

Lê paşê du jinên din jî ketin hundir, jixwe min fam nekir bê ji ku derketin, çûn xwe dan pişt textê wê û xwe bi tiştinan egle kirin. Hingê ez pê hesiyam ku tûleyek jî li ber lingên wê ye, ji min tirê balgîfek e! Pariyek sar bû hundir, belkî jî tenê min hest bi sarbûnê dikir, çiku jinik, çawan bibêjim, şilfîtazî bû (Ozmen, 2020: 132-133).

Xêncî vê, rûpela 135an de em hîn dibin ku dîsa vedigere ser pozîsyona jina ku tezî li ser qenepê ye û bi destê xwe yê çepê ve berzikê xwe dinixumîne, di destê wê yê rastê de kulîlk hene. Xêncî vê, di çîrokê de behsa Afrodîtê ya Tiziano Vecellio, The Rokoby Venus ${ }^{7}$ (1647- 60) ya Diego Velazquez (1599-1660) û Allegory With Cupid ${ }^{8}$ ya Agnolo Bronzino (1503-1572) tê kirin (Ozmen, 2020: 136). Navê tabloya Tiziano Vecellio jî Venus of Urbino ${ }^{9}$ ye. Di pirtûkê de em dibînin ku Venus ya Tiziano Vecellio bi Afrodîtên tabloyên resamên navborî berawird dike vebêjer. Di heman demê de em dibînin ku hem di berga pirtûkê de û hem jî di destpêka rûpela çîrokê de cîh daye Venus ya Tiziano. Bi vî awayî jî di çîrokê de têkiliyeke navbermedyayî pêk aniye.

\subsection{Di roman, çîrok û helbestê de sinema û televîzyon}

Pêşketinên teknîkî bi hev ve girêdayî ne. Yek, ji yeka din re îmkanan diafirîne. Bi vî awayî di serî de fotograf (1825) derdikeve, heftê sal dû re jî (1895) jî sînema dest pê dike û çendekî şûn de, riya televîzyonê vedike.Her çiqas berhem û xebatên edebiyatê ji van pêşketinan pir kevntir bin jî, di serdemên nû de berhemên edebî jî dikevin bin bandora van pêşketinan û hem ji wan re dibin

7http://www.artcityculture.com/sanat/velazquezin-aynadaki-venusu-hakkinda-gercegi-nasil-ogreniriz/

(Dîroka jêgirtinê: 16.11.20)

${ }^{8}$ https://www.tarihlisanat.com/agnolo-bronzino-venus-cupid-alegorisi/ (Dîroka jêgirtinê: 16.11.20)

9https://tr.wikipedia.org/wiki/Dosya:Tizian_102.jpg (Dîroka jêgirtinê: 16.11.20) 
alîkar û hem jî ji wan sûd digirin.Di vê beşê de em dê di edebiyata Kurdî (Kurmancî) de li ser bandora edebiyat, sinema û televîzyonê bisekinin û ji Saturn ya Remezan Alan, Gerîneka Guernicayê ya Yıldız Çakar, Fîtnevîzyon ya Cihan Yildirim û Hêvî û Têkoşîn ya Omîtê Mistefê sûd bigirin.

Saturn a Remezan Alan em dikarin bibêjin di nava romanên Kurmancî de ji ewilîn romanên postmodern e. Di vê pirtûkê de di navbera sînema û edebiyatê de têkiliyên navbermedyayî heye. Dema em bala xwe didin naveroka pirtûkê, di encamê de em dibînin ku lehengek jî romannûs e û romana ku wîn nivîsiye kirine senaryoya sînemayê û beșên heta dawiyê em dixwînin giş jî aîdî sahneyên ku ji romanê dikişînin fîlmê ne:

Stooop!" got li pey wan re dengê Behram, “Aferîm ji we re, aferîm!”

Aktorên ku ji menzîla kamerayê derketibûn, bi eşq û şewq vegeriyan setê. Mîrcin û Helat, yanê Kemal Bekir û Hesen Ehmed jî ji milê çepê de derketin. [...] Alîgira derhêner a ku jeanekî teng lê, makyozê ku lifzek ji zimanê xwe nizaniya, ronîvan û kameravanê ji vî ne cûdatir û kostûmvana Çerkez jî tevî wan bûn (Alan, 2013: 132).

Di romane de ev sûdgirtin û guherandina medyayê ji van hevokên romanê bêhtir diyar dibin: "te bi xwe negot, metna min bûye tiştekî din? min bi çavê lehengekî nivîsandibû, lê wan bi yê hemûyan de, heta bi yê hespekî de jî kişandin fîlmê? [...] lê gelo dema metnek bikeve kirasê senaryoyekê, ê nebe tiştekî din?" (Alan, 2013: 132) Ji van gotinan diyar e ku nivîskar metna xwe bi şêweyeke nû organîze dike û bi serkeftî ji têkiliyên navbermedyayî sûd girtiye. Heta beşa dawî jî ev nediyar e. Lê di beșa dawî de em xwe di nava seta fîlmê de dibînin. Bi vî awayî nivîskar wekî medyayeke cuda ji bo metneke edebî ji sinemayê sûd digire û têkiliya navbermedyayî serkeftî bi kar tîne.

Berhemeke din ya ku ji bo têkiliya sînema û edebiyatê em dê lê binihêrin, romana Hêvî û Têkoşîn a Omîtê Mistefê ye. Di pirtûkê de lehengê romanê Rûken ji lênûska Nezîhî helbestekî dixwîne. Sernavê helbestê "Senaryoya Fîlmekî" ye û çend risteyên destpêkê ev in:

Ger derhênerek bûma

min ê fîlmeke wiha bikşanda:

Helbestvanekî kurd

havînekê

tevî komeke çiyager

derdikeve lûtkeya Korekê (Mistefê, r. 32).

Têkiliya edebiyat û sînemayê di Saturnê de di nava hemû pirtûkê de hatibû belavkirin. Lê di Hêvî û Têkoșînê de tenê sernavê helbestê û naveroka wê bi hunera sînemayê ve eleqedar e. Zêde di têkiliya navbermedyayî de pêşdeçûyinek 
tune. Hinek caran tenê bibîrxistin yan jî bikaranîna nav yan jî têgehekî jî di nava medyayekî de, medyayeke din tîne bîra mirov. Mînak Şehmus Kurt navê pirtûka xwe ya helbestê daniye Tarantîno, Babê Min û Ez. Li vira kesên ku derhênerê navdar Quentin Tarantino yê Amerîkî nas bikin, bi dîtina navê vê pirtûkê re dê berê derhêner Tarantino paşê jî sînema û fîlmên wî bînin bîra xwe. Helbesta ku sernavê xwe daye pirtûkê de jî helbestvan dibêje "tarantîno derhênerekî manyaq / ez ne derhêner ne manyaq / babê min ne ez ne tarantîno” (Kurt, 2020: 28). Ev jî ji bo navbermedyayî ya di navbera helbest û sînemayê de ye. Di heman demê de jî têkilî û meraqa helbestvan ya sînemayê jî nîşan dide. Ji lewre ger helbestvan navê derhênerekî dike sernavê helbesteke xwe û navê pirtûka xwe, ev îmkana vê şîroveyê jî dide me: Helbestvan ji sînemayê hez dike û di nava vê hezkirinê de jî girîngiya Quentin Tarantino heye.

Wekî me li jorê jî got, fotograf, sînema û televîzyon medyayên ku rasterast bi hev re di nava têkiliyê de ne. Di nava vana de ya herî zêde li ser civakê û însanan xwedîbandor televîzyon e. Pierre Bourdieu dibêje di salên 1950an de televîzyon xwedî bandoreke girîng nebû; lê di salên pêş de ji alîyê sembolîk ve jî ji aliyê aboriyê ve jî televîzyon dibe hêza herî zêde xwedî bandor (Bourdieu, 2019: 52). Di nava civaka Kurdan de jî ev bandor em dikarin bibêjin bêhtir ji salên 1990an şûn de zêde bûye. Di vê beşê de em dixwazin bi çend mînakan têkiliya edebiyatê û televîzyonê jî nîşan bidin. Berhema yekem ya ku em dê jê sûd bigirin Fîtnevîzyon (2012) a Cîhan Yildirim e. Peyva "fîtnevîzyon"ê rasterast televîzyonê tîne bîra me.Navê pirtûkê ji sernavê çîrokeka nivîskar tê. Çîroka ku li Stembolê derbas dibe behsa mamosteyekî bawermend dike. Mamosteyekî ciwan li navçeya Sarıgaziya Stembolê di mektebekî de dest bi kar dike. Lê di aliyê baweriyê de hişk e û li ser mijarên cuda ne tenê bi xwendekaran re, bi mamosteyên hevalên xwe yên mesaiyê re jî niqaşên wî pêk tên. Vebêjer mijarê bi van gotinan tîne zimên:

Xwendekarên vê dibistanê tu têkiliya wan bi olê re tune. Li gor wî sedema vê yekê jî televîsyon bû. Li gor wî, televîsyon van civanê me yê xweşik û delal dibir cîhanek xirab. Mamosteyê olê van fikr û ramanên xwe ji derûdora xwe re berdewam digot. Televîsyonê re nedigot televîsyon û yên ku digotin televîsyon, ew ji wan pir dûr dibû. Wî ji televîsyonê re digot "fîtnevîzyon" ango ev televîsyon tijî fîtne û fesadiyê ye! Diva hemû xwendekar ji televîsyonê re bêjin 'fîtnevîzyon' û xwendekarên ku wusa negotana, wî ew ji polê derdixist (Yildirim, 2012: 27).

Navê mamoste di nava xwendekaran de "fîtnevîzyon" dimîne. Lê mamosteyê tiştekî wekî televîzyonê ji xwe re wekî çavkaniya xirabiyan hildibijêre û çîrok li ser vî sernavî tê organîzekirin. Amûrekî ragihandinê û temaşekirinê ku ji dîtbarînê sûd digirê, di çîrokê de wekî amûrekî temsîlî têbikaranîn.

Ji bo navbermedyayiyê em dê ji Hêvî û Têkoşîn ya Omîtê Mistefê jî sûd bigirin. Di beşeke romanê de qasî çar rûpelan behsa bernameyeke televîzyonê 
derbas dibe. Lê di rastiya xwe de ev, bernameyeke xeyalî ye. Ji lewre lehengên romanê Nezîh û Rûkênê dixwazin şanoyeke bi Kurdî binivîsin û vê jî weke bernameyeke televîzyonê amade dikin. Di şanoyê de armanca wan, helbestvanekî ji edebiyatê xeyîdî ye, ji bo zarokên Kurdan îkna bikin ku careke din dest bi helbestnivîsînê bike. Di şanoyê de sahneya ku hatiye organîzekirin di forma bernameya televîzyonê de ye û tê de hevpeyvînek pêk hatiye. Destpêka beșa em qalê dikin, di romanê de bi vî awayî cîh digire:

PÊŞKÊŞVANÊ KURDiSTANTV’YÊ: “Gelî temaşevanên hêja, her wekî hûn jî dizanin em her hefte nivîskarekî kurd dikin mêvanê xwe û li ser edebiyata kurdî bi wî re hevdîtinekê li dar dixin. Mêvanê me yê vê hefteyê jî hesbestvan û nivîskarê navdar Qelenderê Nêço ye. Qelenderê Nêço niha li Îspanyayê dijî û dev ji edebiyatê berdaye. Televîzyona me bi riya telefonê xwe gîhande wî û sozê hevdîtinekê wergirt. Li ser vê yekê nûçegîhanê me yê Barcelonayê Rizgarê Xido bû mêvanê mala wî. Li wê derê li ser navê me jê pirsî û wî jî bersiv da pirsên me. Fermo, hevdîtina me ya bi Qelenderê Nêço re temaşe bikin!

RIZGARÊ XIDO: Apê Qelender, li ser navê Kurdistan TVyê ez sipasiyên xwe pêşkêşî cenabê te dikim (Mistefê, r. 47).

Di dewama vê beşê de Qelenderê Nêço jî bi sipasiya Kurdistan TVyê dest bi axaftina xwe dike û bi vî awayî hevpeyvîn bi pirs û bersiv didome wekî di televîzyonê de pêk tê. Em di van diyalogan de uslûba televîzyonê rasterast dibînin (Mistefê, r. 47-50). Mistefê sê medyayên wekî şano, televîzyon û edebiyat bi hev re bi kar aniye. Di çîroka Mehmed Şarman ya bi sernavê "Axaftina Nobelê" de jî em dibînin ku serlehengê çîrokê xwe wekî ku xelata Nobelê wergirtiye xeyal dike û axaftina xwe de van dibêje: "Ji xwe re got û çû li ser qompîtirê rûnişt. Gelî temaşevanên hêja... (Gelo ev peyv zêde nehatiye bikaranîn? Ez tiştekî din nebêjim. An na? Ne xeme lo. Ma wan bêbavan çend caran Roj tv temaşe kirine...) [...] Çavên wî bi qompîtirê re dizeliqî" (Şarman, 2016: 13) Di vê çîrokê de di gotina lehengê çîrokê ya "Gelî temaşevanên hêja..." bandora şêweya televîzyonê tê dîtin.

Di romana Gerîneka Guernicayê de têkiliyên navbermedyayî bi alîkariya televîzyonê pêk tê. Di romanê de televîzyon wekî leîtfotîfekî ye û em dikarin bibêjin berdevkî û vegotina dewletê temsîl dike. Di romanê de hevoka yekem ev e: "Wek her carê dîsa televîzyon vekirî bû" (Çakar, 2016: 11). Ango roman bi televîzyonê û bi dîmenên mirin, kuștin û xwînê dest pê dike. Ekranê televîzyonê hertim bi dîmenên xwîn, şewat, mirin, kuştinê ve tijî ye.

Lê televîzyon hertim vekiriye û pêşkêşvana lêvmor û porzer her û her li ser ekranan bi xeberên felaketan, mirin, kuştin, şewat û xwînê di ser temaşevanan de direşîne. Vebejêr vê rewşê bi van hevokan tîne zimên: 
Wek her carê, vê sibê jî televîzyon vekirî ye. Dîsa jinika porzer û lêvmor. Ax, dîsa dûbarekirina zemên: 'Li herêmê, 200 terorîst hatin kuştin. Hezar gund hatin şewitandin!!!'

Li pişt camekanê, pêşkêşvanekê her roj dîmenek rast nîşan bida jî, agahiyeke derew li ser dinivîsand, an agahiyeke rast pêşkêş bikira jî, dîmenekî çêkirî nîşan dida. Êdî kujerên bi çek ên li taxan, bûnin pêşkêşvan û li pişt camekê her roj guleyên xwe bera mejîyên me didin. Em pê namirin, lê em tim birîndar dibin. Min nizanîbû ruhê ku carekê birîndar bû êdî baş nabe (Çakar, 2016: 41).

Bi vî awayî bandora televîzyonê heta dawiya romanê didome. Çawa di destpêka romanê de televîzyon heye, di rûpela dawî ya romanê de jî hevoka, "Televîzyon vekirî bû" (Çakar, 2016: 210) cîh digire. Bi vî awayî di romanê de di navbera televîzyon û edebiyatê de têkiliya navbermedyayî zêde zêde derdikeve pêş. Nivîskar, amûrekî bi kar tîne ku ewqas zêde di jiyana me de cîh digire û piraniya caran berdevkîya desthilatdaran dike. Guy Debort ji bo vê rewşê dibêje, "Civaka ku barkêşê temaşeyê ye, herêmên kêmpêşketî tenê bi hegemonyaya îktîsadî ve hilnade binê desthilatdariya xwe. Wekî civaka temaşeyê li wan hikm dike (Debort, 1996: 33)." Di romanê de jî em dikarin mîsyona televîzyonê û jina porzer-lêvmor bi vê şîroveyê ve girêdin. Ji lewre ew her dem agahiyan bi çav û nêrînên desthilatdaran bi monotomiyeke robotîk vedibêje. Ji hest û ramanan dûr dixûyê. Pierre Bourdieu dibêje "Televîzyon, şiklê hizirkirina beșeke mezin ya civakê dike binê bandora xwe." (2019: 20); lewre ew "amûrek e ku heqîqetê diafirîne." (2019: 25). Di romana Çakar de jî televîzyon, heqîqeta bi perspektîfa desthilatdaran afirandî, dixwaze bi hemû civakê bide pejirandin.

\subsection{Medyaya înternetê û yên din}

Em dikarin bibêjin berhemên edebî, gelek caran wekî neynika serdema xwe ne. Di wan de gelek taybetiyên nivîskaran û serdemê em dikarin bibînin. Mînak, ji ber sedemen cuda, em şiklên rêveberiyê, bawerî, avahîsazî, pergala hiqûqê, aboriyê û pêşketinên teknolojiyê di berhemên edebî de dibînin. Di vê peywendê de dema em li metnên ku me ji bo lêkolînê tercîh kirine binihêrin, em dikarin şopên pêşketinên teknîkî û yên di qada ragihandinê de pêk hatine bibînin. Bi taybet jî bi pêşketinên înternetê re, wekî her qadê di berhemên edebî de jî şop û bandora înternetê tê dîtin. Armanca me ya vê beșê jî ew e ku em di çend berhemên Kurdî (Kurmancî) de bandora înternetê û medyayên din tesbît û tehlîl bikin.

Di Belkî l̂şev Biniveyê de Murat Bayram xêncî di nava nivîsê de bikaranîna fotografan, di çîrokan de têgeh û amûrên fotokêşiyê û yên rojnamevaniyê jî gelek caran bi kar aniye û bi vî awayî jî navbermedyayî pêk anîye. Mînak, di çîroka "Belkî" de hevoka destpêkê ev e: "Jineka nîvsere, bi kela giriyî li ber xaniyekê xerabûyî li pêş kamêrayê diaxivî” (Bayram, 2018: 15). Di çîroka "Hişş be!” de "Rojnameger nizane ka dayika Cizîrî karî bebika xwe binivîne an no" (Bayram, 
2018: 19). Di çîroka "Hestiyên reș!” de "Rojnameger wek gêjekê ketibû di nav kolanan de û hima çi bidîtiyan wêneyên wan digirtin”. Di “Ez û mirin cotek in!” de "Li têlefona xwe nêrî, saet kontrol kir [...]" (Bayram, 2018: 25). Di "Yê bizanin ku ez dikenim!" de "Keçikê ji şaşeya televîzyona di metroyê de li psîkên şirîn dinêrî" (Bayram, 2018: 29). Di “Tahîr Elçî: Delalê min!” de "Wek hemî kesan Rojnameger jî bêhêvî bû ku bikare di qedexeyê de biçe Cizîrê. Xetên telefon û înternetê hatibûn astengkirin" (Bayram, 2018: 31). Di "Navê wê Helîm e" de "Mîkrofona di destên rojnamegerî de, taxima cilikên wî, qundireya ku qet li wê axê û wan şertan nedihat eşkere dikir ku ew rojnameger e. [...] Ez naxwazim ji televîzyonan re biaxivim" (Bayram, 2018: 35). "Mirina saetê: 08.05" de "Rojnameger û kameraman, man bi tenê. [...] Ji kamêre û mîkrofonan diyar bû ku rojnameger bi çi mexsedê li wê derê ne" (Bayram, 2018: 45). Bi vî awayî bi dehan mînak hene ku amûr û têgehên (wekî mîkrofon, kamera, rojnameger) aîdî medyayên ragihandinê, medyayên televîzyon û rojnamegeriyê ne, di pirtûka Bayram de derdikevin pêş û ev jî têkiliya navbermedyayî zêdetir dikin.

Di çîroka Mehmed Şarman de jî di van hevok û komepeyvan de behsa medyayên din derbas dibin: "Dîsa jî ji şerman kovar bi nîzamî distand û dîanî mal.", "Nivîsa wî di kovarekî de hatibû weşandin.”; “Li bayiyekî qeztefiroș kovarekê dabû destê xwe, [...]" (r. 15); "[...] bi telefonê mizgînî dabû wan.", "Ji nav nivînan rabû û çû ser qompîtirê [...]" (r. 16). Di peyv û komepeyvên me reş nivîsîne de jî medyayên cuda derbas dibin û bî avayî di navbera metneke edebî û medyayên din yên ragihandinê de têkiliya navbermedyayê pêk tê.

Di beşa destpêkê de me bala xwe dabû pêşketinên di medyaya nû û behsa platformên wekî Facebook, Google, Twitter, Youtube, Skype, Wikipedia, WhatsApp, Instagramê kiribû. Di berhema Omer Faruk Baran ya bi navê Şeveke Îstismar de jî tê dîtin ku lehengê wî van platformên medyaya nû pir aktîf bi kar tîne.Dema serleheng û hevalê wî li kafeyê rûdinin, keçek bala serleheng dikişîne. Serleheng dixwaze fotografên wê bikişine û rewş bi van gotinan hatiye îfadekirin: "Loma min makîneya xwe ya nû ya min di ser Letgoyê re bi 50 lîreyî kirîbû, ji ser maseyê rakir raberî wî kir û got 'Fotograf, wekî din ne tiștek” (Baran, 2019: r. 13). Pișt van gotinan serleheng dibêje, "[...] min jî Whatsapp vekir û seba ku paşê li serê min nebe bela ji Sûrettîn re nivîsî: 'Dibe ku ez îșev nêm. Li benda min memîne, xirrî xwe mêşîne:)" (Baran, 2019: 13-14). Wekî di van gotinan de tê dîtin ne tenê navê platformên medyaya nû yên wekî Letgo û WhatsApp, lê di heman demê de uslûba wan jî di metneke edebî de cîh digire: di dawiya hevokê de sembola ken hatiye bikaranîn. Ango medyaya nû bi xwe re formên nû yên vegotinê jî diafirîne û ev bandorê li medyayên din jî dikin ku li vira bandora wê ya li ser berhemeke edebî em dibînin. Serleheng fotografê ku me li jorê qalê kir ya keça ku cixarê dikişîne di platforma instagramê de parve dike (Baran, r. 15). Li ser vê fotografê bi hevalê xwe re bi riya platforma WhatsAppê diaxive ango bi alîkariya nivîsê û paşê jî jê re telefonê vedike ku ev jî amûreke ragihandinê ya nû ye û têlefonên berikan, êdî parçeyeke nebenabe ya jiyana nû ne. Dû re keçika ku bala serleheng kişandiye ji kafeyê derdikeve û serleheng jî dide pêy wê: 
Me qehwe derbaz kirin bi şûn de, xezala şêr li pey wê, li gor belgefîlman gerek êdî guhên xwe miç bikirana. Diviyabû ez li pişt xwe hîs bikirama û çerx bûya binêriya. Lê ew nezivirî. Ku nezivirî, vîdeoyên DiKAD û Navenda Mafên Jinan a Baroya Amedê yên li ser tundûdijîtiya dijî jinan çêkiribûn hatin bîra min (Baran, 2019: 19).

Di nava van hevokan de "belgefîlm" û "vîdeo" û di dewama rûpelê de jî Twitter, selfy, kompîter derbas dibin ku ev jî dîsa aîdî serdema medyaya nû ne. Di rûpela 27. de ji bo guhdarkirina straneke Abbas Ahmed dikeve Youtubeê û wêneyên ku hevalê serleheng li ser WhatsAppê bi xeletî dişîne di têlefona xwe di ferq dike û ji hevalê xwe re telefonê vedike. Di dawiya pirtûkê de jî serleheng diçe otêlê, di televîzyonê de kanala TRT Haberê vekirî ye (r. 32). Em ji van mînakan jî dibînin ku di berhemeke kurt de Omer Faruk Baran zêde zêde cîh daye platformên medyaya nû. Youtube, instagram, WahtsApp, twitter, selfy, kompiter, televîzyon, fotograf, vîdeo, belgefîlm, telefona berikê û kompîter ango bi hemû rê û amrazên serdema nû û medyaya nû ve berhema wî berhemeke serdema nû ye. Divê em vê jî lê zêde bikin ku nivîskar ne tenê behsa van dike, di heman demê de ji uslûba ku van platforman bi xwe re anîne jî sûd digirê. Bi hevokên wan û îmajên ku bi wana derhetine holê bi kar tîne.

Di berhema Mistefê de nivîskar ji sê medyayên wekî telefon, şano û televîzyonê di nava medyayeke din ango di nava berhemeke edebî de bi kar aniye. Di romanê de leheng (Nezîh û Rûken) li ser înternetê lêkolînê dikin û ev jî dîsa ji di nava berhemeke edebî de îşareta têkiliyê navbermedyayî ye (Mistefê, $r$. 50) û em vê jî dikarin wekî nîşaneyên medyaya nû ya di metnên edebî de nîşan bidin.

Berhema dawî ya ku em dê li ser biseknin Cemîlê Nîgarkêş û Heft Qambihostên Dewletê ya Şener Ozmen e. Nivîskar di vê pirtûka xwe de mînakeke bikaranîna medyayên înternetê di çîroka xwe de bi kar aniye. Li vira xala ku em dixwazin balê bikişînin ser di nava çîrokê de bikaranîna sembola ku wekî (\#) hashtag tê binavkirin e. Sernavê çîroka ku em dê li ser bisekinin "\#jinikaciwanabitenê" ye û ji hashtag û komepeyvekê pêk tê. Di nava çîrokê de em dibînin ku vebêjer jinekê li ser înternetê dişopîne ku ev jin bi \#jinikabitenê hashtag vekiriye û parvekirinan dike (Ozmen, 2020: 125). Lê ne tenê li vir, di nava çîrokê de di dawiya gelek paragrafan de jî wekî peyvên nifteyî yên wê beşê yan jî paragrafê, bi hashtagê hene. Mînak di dawiya paragrafa destpêk a çîrokê de ev hashtag cîh digirin: \#corona \#imagine \#imagination \#vision \#blog \#model, \#dream \#dress (Ozmen, 2020: 123). Di paragrafeke kurt de em dikarin mînakê bidin: "Haaa, çîrokek jî nivîsandiye! Hem jî ji bo kovareke femînîst!? Ez û Yezdan hîn jî di ber hev didin... \#çîrok \#yezdan \#jin” (Ozmen, 2020: 129). Bi vî awayî di çîrokê de bi giștî 111 (sed û yanzdeh) caran sembola hashtagê hatiye bikaranîn. Ev jî di metneke edebî de bandora çanda înternetê û medyayên înternetê rasterast û pir zelal nîşan dide. Xêncî vê çend peyvên ku di nava çîrokê de têkiliya navbermedyayiyê tîne bîra mirov jî hene. Mînak, "peykerê Afrodîtê" (r.123); 
"vîdeo", “objektîf”, “Hip Hop” (r.125); "televîzyon, telefon (r. 126); "wêne” û "poster" (r.128-129). Diyar e ku nivîskar çîroka xwe bi zaneyî bi hêman amrazên medyayên cuda ve xemilandiye û têkiliyeke navbermedyayî pêk anîye.

\section{Encam}

Edebiyat gelek caran mîna neynika civakê ye, bi her avayî taybetîyên civakê di nava xwe de dihewîne. Di heman demê de jî wekî medyayekê tê pejirandin û bikaranîn; helbet edebiyat û berhemên edebî bi medyayên din re di nava danûstêndinê de ne. Di berhemên edebî yên Kurmancî de ku ji cureyên wekî roman, çîrok û helbestê pêk tên, nivîskarên Kurd hem ji aliyê naverokê hem jî ji aliyê uslûbê ve ji medyayên cuda îstifade kirine. Berhemên edebî yên ku em li ser xebitîn de me dît ku ji hêmanên dîtbarî zêde sûd girtine. Li hember "bilindbûna çanda dîtbarî” nivîskarên Kurd jî bêdeng nemane. Çawa ku di roman, çîrok û helbestan de resim, fotograf û dîmen hebûn yan jî behsa wan derbas dibû, ligel wan televîzyon, afîş û pêşketinên medyayên nû yên wekî whatsApp, youtube, instagram hwd. Jî di nava berheman de derbas dibûn. Nivîskarên Kurd, guherînên jiyanê û pêşketinên ku daxilî jiyana me bûne di nava metnên xwe de bi kar tînin û bi vî awayî wan guherînan em dikarin ji berhemên wan bişopînin. Li aliyê din jî wan nivîskaran ji bo edebiyatê ji medyayên din îstifade kirine û hem xwestine îmkanên medyayên din ji bo edebiyatê bi kar bînin hem jî bi vê re xwestine berhemên xwe bi têkiliyên medyayên din ve pir-reng û pir-deng bikin. $B \dot{i}$ vî awayî hem dê bikaribin peyamên xwe bi alîkariya medyayên cuda bêhtir bigihînin xwendevanên xwe û hem jî di metnên xwe de guherînan bikin, metnên xwe ji monotoniyê dûr bixin.

\section{Çavkanî}

Ağıl, N. (2015). Ekfrasis - Batı'da ve Bizde Görsel Sanatın Sözle Tasviri. İstanbul: Simurg Yayınları.

Apaydın, M. (2002). Biyografik roman türünün Türk edebiyatındaki gelişimi üzerine bazı dikkatler. HeceTürk Romanı Özel Sayısı. 65-66-67, 460-469.

Arslan, F. (2016). Metinsel melezleşmeye doğru medya / medyalararasılık ve öteki türler. The Journal of Academic Social Science Studies. 52, 49-56.

Aytaç, G. (2002). Edebiyat ve Medya - Kitaptan Ekrana Edebiyat. Ankara: Kültür Bakanlığı Yayınları.

Baran, O. F. (2009). Şeveke Îstismar. İstanbul: Weşanên Avesta.

Bayram, M. (2008). Belkî îşev binive. İstanbul: Weşanên Avesta.

Bedir-Han, M. S. (1998). Defter-i Â'malım. (Hazırlayan: Mehmed Uzun - Rewşen Bedir-Han). İstanbul: Belge Yayıncilık.

Bedirxan, C. A. (1997). Günlük Notlar (1922-1925). İstanbul: Avesta Yayınları.

Bedirxan, H. E. (2013). Albuma Bedirxaniyan, Erbil: Weşanên Dezgeha Çap û Weşanxaneya Bedirxan.

Bedirxan, R. (2009). Dotmam. Stembol: Weşanên Avesta.

Berger, J. (2009). Görme Biçimleri. (Çev. Yurdanur Salman). İstanbul: Metis Yayınları. 
Bourdieu, P. (2019). Televizyon Üzerine. (Çev.Alper Akım). İstanbul: Sel Yayıncılık. Canatak, A. M. û Bulduk, N. (2019). Dijital Çağ Türk Edebiyatı ve Medyalararasılık Tartışmaları. İstanbul: Hiper Yayıncılık.

Çakar, Y. (2016). Gerîneka Guernicayê. Diyarbakır: Weşanên Lîs.

Debord, G. (1996). Gösteri Toplumu ve Yorumlar. (Çev. Ayşen Ekmekçi - Okşan Taşkent). İstanbul: Ayrıntı Yayınları.

Elleström, L. (2010). The modalities of media: a model for understanding intermedial relations. Media Borders, Multimodality and Intermediality. (Edit. Lars Elleström). Londra: Palgrave Macmillan.

Hony, H.C. û İz, F. (1993). The Oxford Turkish-English; English-Turkish Dictionary. İstanbul: Oxford University Press - İnkılap Kitabevi Yayınları.

Kayaoğlu, E. (2006). Murathan Mungan'ın Paranın Cinleri'nde Medyalararasılık.Bellek Mekân İmge - Prof. Dr. Nilüfer Kuruyazıcı'ya Armağan. (Yay.Haz.Mahmut Karakuş- Meral Oraliş). İstanbul: Multilingual Yayınları.

Kayaoğlu, E. (2009). Edebiyat Biliminde Yeni Bir Yaklaşım Medyalararasılık. İstanbul: Selenge Yayınları.

Keleş, A. û Can, M. Z. (d.t.). Medya Kavramına Bir Bakış ve Iletişimin Estetik Bir Medyası Olarak Edebiyat.Navnîşana

jêgirtinê:https://www.academia.edu/30015544/Medya_Kavram\%C4\%B1na_Bir_Ba k\%C4\%B1\%C5\%9F_ve_Estetik_\%C4\%Boleti\%C5\%9Fimin_Bir_Medyas\%C4\%B1_Olar ak_Edebiyat (Dîroka jêgirtinê: 04.11.2020)

Korat, G. (2012). Dil Edebiyat ve İletişim. İstanbul: Illetişim Yayınları.

Kurij, S. (1996). Nivîskarê Kurd Mehmed Uzun Re Hevpeyvînek. M. Uzun. Ziman û Roman. Weşanên Nûjen.

Kurt, Ş. (2020). Tarantino Babê Min û Ez. Stembol: Weşanên Avesta.

Lynton, N. (1982). Modern Sanatın Öyküsü. (Çev. Cevat Çapan - Sadi Öziş). İstanbul: Remzi Kitabevi Yayınları.

McLuhan, M. (2002). Gutenberg Galaksisi - Tipografik İnsanın Oluşumu.(Çev. Gül Çağalı Güven). İstanbul: YKY.

Mistefê, O. (d.t). Hêvî û Têkoşîn. (Cîh û dîroka weşanê tune).

Mungan, M. (2008). Cinên Pereyan. (Wer. Felat Dilgeş). Stembol: Weşanên Doz.

Noel, E.W. C. (2014). Kürdistan 1919. ( Çev. Bülent Birer). İstanbul: Avesta Yayınları.

Nora, P. (2006). Hafiza Mekânları. (Çev. Mehmet Emin Özcan). İstanbul: Dost Kitabevi Yayınları.

Ozmen, Ş. (2020). Cemîlê Nîgarkêş û Heft Qambihostên Dewletê.Stembol: Weşanên Avesta.

Reş, K. (2013). Bajarê Cizîra Botan û Hunera Mîr Bedirxan. Mersin: Weşanên Azad. Sontag, S. (2008). Fotograf Üzerine. (Çev. Reha Akçakaya). İstanbul: 6.45 Yayınları..

Şarman, M. (2016). Axaftina nobelê.Pirça Winda.Stembol: Weşanên Avesta. 
Navbermedyayî: Di Edebiyatê De Arasteyeke Nû û Ji Edebiyata Kurdî ya Kurmancî Çend Mînak

Toklu, M. O. (2008). Türk şiirinde medyalararasılık: çağdaş Türk şiirleri örneğinde. Yaşamak eşittir Yazmak - Gürsel Aytaç Kitabı. (Ed. Sevil Onaran). Ankara: Hece Yayınları.

Uzun, M. (2002). Bîra Qederê. Stembol: Weşanên Avesta.

Uzundemir, Ö. (2010). İmgeyi Konuşturmak - İngiliz Yazınında Görsel Sanatlar. İstanbul: Boğaziçi Üniversitesi Yayınları.

Yildirim, C. (2012). Fîtnevîzyon. Stembol: Weşanên Pêrî.

Şekîl 1: https://www.slideshare.net/serdar_urcar/web-30-10249811 (Dîroka jêgirtinê: 26.06.20) 